
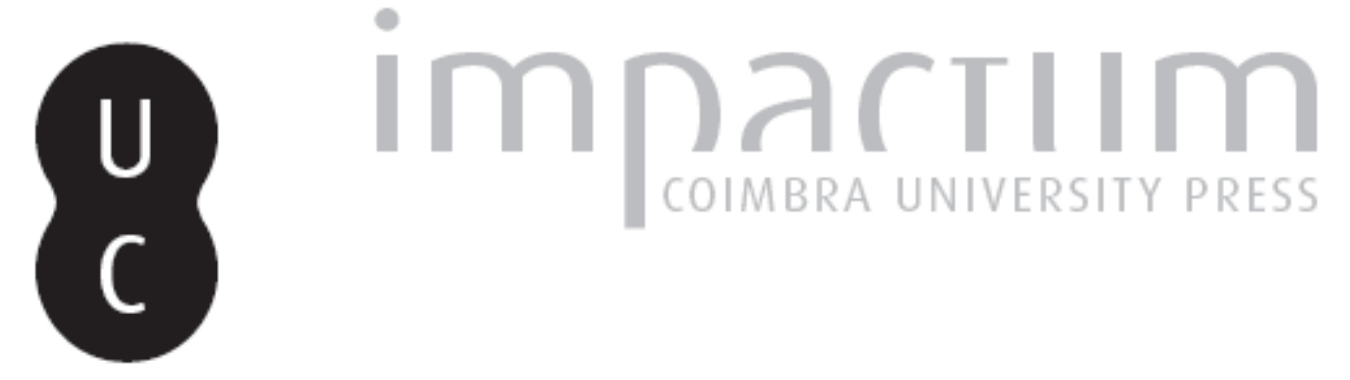

\title{
Imagem e afirmação estratégica de Coimbra: breve reflexão
}

\section{Autor(es): $\quad$ Gaspar, Carolina Goucha}
Publicado por: Faculdade de Letras da Universidade de Coimbra, Departamento de Geografia

URL persistente:

URI:http://hdl.handle.net/10316.2/30221

DOI:

DOI:http://dx.doi.org/10.14195/0871-1623_32_17

Accessed : $\quad$ 26-Apr-2023 12:39:47

A navegação consulta e descarregamento dos títulos inseridos nas Bibliotecas Digitais UC Digitalis, UC Pombalina e UC Impactum, pressupõem a aceitação plena e sem reservas dos Termos e Condições de Uso destas Bibliotecas Digitais, disponíveis em https://digitalis.uc.pt/pt-pt/termos.

Conforme exposto nos referidos Termos e Condições de Uso, o descarregamento de títulos de acesso restrito requer uma licença válida de autorização devendo o utilizador aceder ao(s) documento(s) a partir de um endereço de IP da instituição detentora da supramencionada licença.

Ao utilizador é apenas permitido o descarregamento para uso pessoal, pelo que o emprego do(s) título(s) descarregado(s) para outro fim, designadamente comercial, carece de autorização do respetivo autor ou editor da obra.

Na medida em que todas as obras da UC Digitalis se encontram protegidas pelo Código do Direito de Autor e Direitos Conexos e demais legislação aplicável, toda a cópia, parcial ou total, deste documento, nos casos em que é legalmente admitida, deverá conter ou fazer-se acompanhar por este aviso.

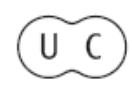




\title{
Imagem e afirmação estratégica de Coimbra: breve reflexão
}

\author{
Carolina Goucha Gaspar \\ Câmara Municipal de Coimbra. \\ carolinagg@sapo.pt
}

\section{Resumo:}

No contexto global, o sistema urbano organiza-se numa lógica de relações de cooperação e competitividade entre os territórios. Neste jogo, a construção de uma imagem positiva é um fator decisivo para a captação de novos atores (ex. turistas ou até residentes) capazes de conduzir à territorialização de mais-valias. A imagem desempenha assim um papel importante no planeamento, pois auxilia a produção de uma representação positiva e sedutora do território afastando-o de uma reprodução simplificada e estereotipada. A conceção de uma imagem mais atraente para a população local e agentes externos, surge assim como estratégia fundamental para a construção de um território ativo e atrativo, e consequentemente para a sua afirmação. O presente artigo pretende constituir uma breve reflexão e análise de conteúdo (ex. protagonistas, reflexões, diálogos das personagens, lugares onde desenrola a ação) sobre uma das representações orgânicas de Coimbra: o filme "O Rasganço".

Palavras-chave: Globalização. Competitividade. Afirmação estratégica. Imagem.

\section{Abstract:}

Image and place development of Coimbra: a brief reflection

In an overall view, the urban system is organized by way of logical relationships of cooperation and competition among neighborhoods. In this contest, the build up of a positive image is a decisive factor for attracting active elements, be they tourists or locals, capable of stimulating local services. The image has a crucial role in the overall planning for it is capable of bringing novelty and of slighting standardized and oversimplified patterns of representation. The conception of an image attractive to both, local residents and outsiders, is thus a basic strategy for the enhancement of a given region. The present work is the resultant of a brief reflection and analysis (ex. dialogues, characters, places) on one of Coimbra's most vivid portraits-the film "O Rasganço".

Keywords: Globalization. Competition. Place development. Image.

\section{Résumé:}

Image et afirmation strategic de Coimbra: breve reflection

Dans un contexte global, le système urbain s'organise dans un rapport logique de coopération et de concurrence entre les territoires. Dans ce jeu, la construction d'une image positive est un facteur décisif pour attirer de nouveaux acteurs (par exemple, des touristes ou même des résidents) qui peuvent conduire à des gains territoriaux. L'image joue, ainsi, un rôle important dans la planification, dans la mesure où elle aide à la production d'une représentation positive et séductrice, s'éloignant d'une reproduction simplifiée et stéréotypée. La conception d'une image plus attrayante pour la population locale et les agents externes apparaît donc comme une stratégie fondamentale visant la construction d'un territoire actif et attractif, en d'autres thermes pour son affirmation. Cette article prétend constituer une brève réflexion sur l'une des représentations organiques de Coimbra : le film "Rasganço".

Mots-clés: Globalization. Concurrence. Afirmaction strategic. Image. 
A importância da imagem enquanto instrumento na afirmação estratégica de um território

O processo de globalização contribui para uma realidade desigual e instável, na qual os lugares estabelecem entre si relações de cooperação, mas também de competitividade. Os espaços geográficos (ex. cidades) procuram afirmar-se enquanto territórios atrativos para a captação de novos residentes, turistas, investidores, entre outros (Baker, 2007; Kotler et al, 1993; Avraham e Ketter, 2008).

Neste contexto, a afirmação de um espaço geográfico não depende apenas dos recursos que detém mas da forma como se comunica com os agentes de desenvolvimento, ou seja, resulta de um conjunto complexo de técnicas de marketing territorial. A "implementação profissional da marca territorial é um instrumento eficaz de desenvolvimento local, que promove a atividade de exportação, traz mais turistas, resulta de uma força de trabalho competente e atrai investimentos" e a "reputação e a imagem de um lugar é o ativo mais valioso e uma futura fonte de riqueza para os residentes. Aumenta a autoestima dos moradores, mobiliza o orgulho cívico, torna as pessoas conscientes e orgulhosas das conquistas da sua terra" (RAINISTO, 2010: 8), uma vez que, neste processo de sedução dos lugares, para além dos recursos endógenos (materiais e imateriais), é relevante a participação da população local, no sentido de esta se tornar representante do território no exterior, visando deste modo fomentar todo o processo de atratividade do espaço geográfico. Neste caso, quanto maiores forem os níveis de autoestima, orgulho cívico e sentido de pertença ao lugar (topofilia), maior será o orgulho na cidade, assim como o compromisso de cidadania.

É neste cenário que, enquanto instrumento de marketing territorial, a representação dos lugares assume importância estratégica.
Autores como Avraham e Ketter (2008) referem que a imagem de um território resulta de crenças, ideias, impressões individuais sobre determinado espaço geográfico, e é estruturada mediante diferentes objectivos: manutenção de uma imagem positiva do território; afirmação da identidade de um lugar até agora enfraquecida ou recuperação de uma imagem positiva e actractiva que, por motivos circunstanciais (ex. crise económica, atentado terroristas, catástrofe natural, etc.) foi alterada.

A mais, a imagem de um território deve ainda ser entendida como "(...) estar associada à consolidação de uma identidade local que responda a um sentimento de pertença com base em padrões sociais, ambientais, culturais geográficos (...), como afirmam AzEvEDo et al. (2010: 90), sendo esta construída mediante a valorização do património material e intangível, dos meios e serviços de um território.

Tratando-se o "modelo estrela" (Figura 1), de uma representação cognitiva, onde a imagem de um lugar é representada por um esquema (estrela), desenhado por retas principais (representativos dos eixos de identidade centrais do espaço geográfico) e interceptado por outras de menor intensidade (representação de outras características do território), esta pode assumirse como "intensa" quando esta é representa por vários eixos de identidade (lugar B) ou "enfraquecida" quando é definida apenas por 2 ou 3 eixos de identidade. (lugar A). E, o lugar A pode ser convertido em lugar B através do marketing de outros eixos de identidade.

De facto, este modelo permite representar territórios com uma imagem estereotipada e concluir que um lugar com uma maior diversidade de eixos de identidade conduz a uma menor focalização dos seus aspectos problemáticos (fragilidades).

Enquanto instrumento de afirmação estratégica de um território, a imagem de um espaço geográfico,

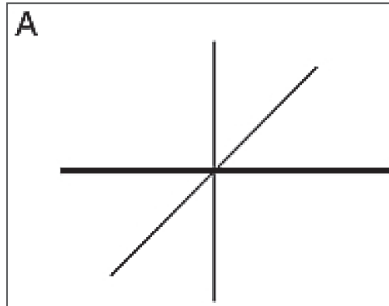
A place with a poor image: one dominant trait

B

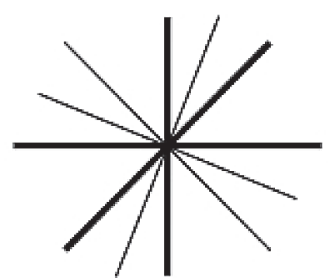

A place with a rich image: numerous facets and three dominant traits 
além de se assumir como um conceito complexo, não resulta apenas de campanhas formais de marketing territorial (imagem induzida); de mensagens informais, quase sempre veiculadas pelas indústrias culturais (imagem orgânica); mas também de impressões recolhidas por experiências diretas.

\section{Algumas representações de Coimbra. 0 caso de "Rasganço", filme de Raquel Freire}

Ao longo de décadas, a cidade de Coimbra tem sido representada através de diferentes mensagens informais (ex. obras literárias, documentários, produções cinematográficas, entre outras). Desde autores como Almeida Garrett, Eça de Queirós, para quem a cidade e as vivências académicas contribuíram para a formação da sua personalidade cultural e obras literárias, a Miguel Torga, que se assumiu como crítico da praxe académica e cuja paisagem e ambiente sociocultural da cidade surge presente na obra "Diário", em produções líricas e ficção narrativa do escritor, a urbe de Coimbra tem vindo a ser representada também através do cinema. 0 caso da longa metragem "Capas negras" (de 1947), que retrata o espírito, o ambiente académico e social da cidade e o património intangível associado às repúblicas universitárias; do filme "Inês de Portugal" (1997), que aborda momentos e personalidades de relevo histórico da cidade, e de outras películas mais recentes.

"Rasganço", filme realizado por Raquel Freire em 2001, surge como uma imagem orgânica de Coimbra, de grande interesse não só pela sua passagem em vários festivais de cinema (portugueses e estrangeiros), pelo número de espectadores mas, sobretudo, pela forma como a cidade é representada.

Considerado o segundo filme com mais espectadores em Portugal no ano de 2001, "Rasganço" foi visualizado quer, em salas de cinema do território nacional quer, no estrangeiro, nomeadamente França. Ao percorrer vários Festivais cinematográficos internacionais, como é caso do Festival de Veneza - Semana internacional da crítica (2001), Festival Internacional de Montreal (2001), Mostra internacional de cinema de Valência (2002), Festival internacional de cinema de Gwajun, Coreia (2002), Festival Primer Plano Dijon (2002), II Festival de Cinema Ibérico e Europeu, assim como no I Festival internacional de cinema de Braga (2003), o filme de Raquel Freire, contribui para uma ampla divulgação da imagem de Coimbra.

A narrativa do filme centra-se no percurso de Edgar. Jovem que chega de Lisboa e, seduzido por
Coimbra e pelo seu ambiente cultural singular, procura entrar na Universidade e na sua "atmosfera", pautada de tradições excepcionais. Todavia, porque todos the fazem notar que "está fora", este não consegue fazer parte do espírito académico e começa a cometer uma série de atos violentos sobre jovens universitárias.

Tratando-se "Rasganço", de uma película integralmente filmada em Coimbra, ao analisar o conteúdo desta produção fílmica, é possível aferir que esta percorre lugares e geosímbolos (ex. Torre da Universidade, Escadas Monumentais, Porta Férrea, Tumulo de D. Afonso Henriques, entre outros) da cidade que remetem, através do património material, para um período de grande afirmação estratégica da urbe.

A ação decorre sobretudo no Pólo I da Universidade e no núcleo antigo de Coimbra, sendo este o cenário dos principais acontecimentos da narrativa. Este espaço emblemático apresenta-se como local representativo do espírito e tradições académicas, de partilha de experiências e união dos estudantes, mas também como lugar de segregação social, pois surge como território de escolha das vítimas de Edgar. As ruas sinuosas da "Alta" da cidade aparecem associadas às tradições estudantis (ex. serenatas); a Associação Académica de Coimbra como local de encontro de estudantes; as Repúblicas Universitárias como lugares de diversão e de partilha de ideias e as ruas do Pólo I da Universidade, associadas a uma imagem repulsiva, aparecem como palco dos episódios de exclusão sofridos por Edgar e de atos violentos exercidos sobre as estudantes universitárias.

Apesar da narrativa de "Rasganço" se centrar essencialmente na velha Almedina de Coimbra (Figura 2), a sua ação decorre, ainda embora com pouca importância para a o seu desenvolvimento, em outros lugares emblemáticos e simbólicos da cidade. Trata-se do caso da Igreja de Santa Cruz, do Mosteiro de Santa Clara-aNova e da Mata Nacional do Choupal.

A análise de conteúdo do filme permite ainda verificar que os seus protagonistas encontram-se carregados de simbolismo. O recém-chegado Edgar representa a revolta por uma sociedade coimbrã hierarquizada e intolerante, simbolizando assim os "excluídos", aqueles que sofrem de segregação por não frequentarem um curso superior; Maria dos Anjos, personagem representante do provincianismo e de uma mentalidade pautada por complexos de inferioridade; Ana Rita, estudante finalista do curso de direito do ensino superior, simboliza o espírito académico e cultural característico de Coimbra e, último, a personagem Dr. ${ }^{a}$ Zita surge como uma referência à sociedade elitista coimbrã. 


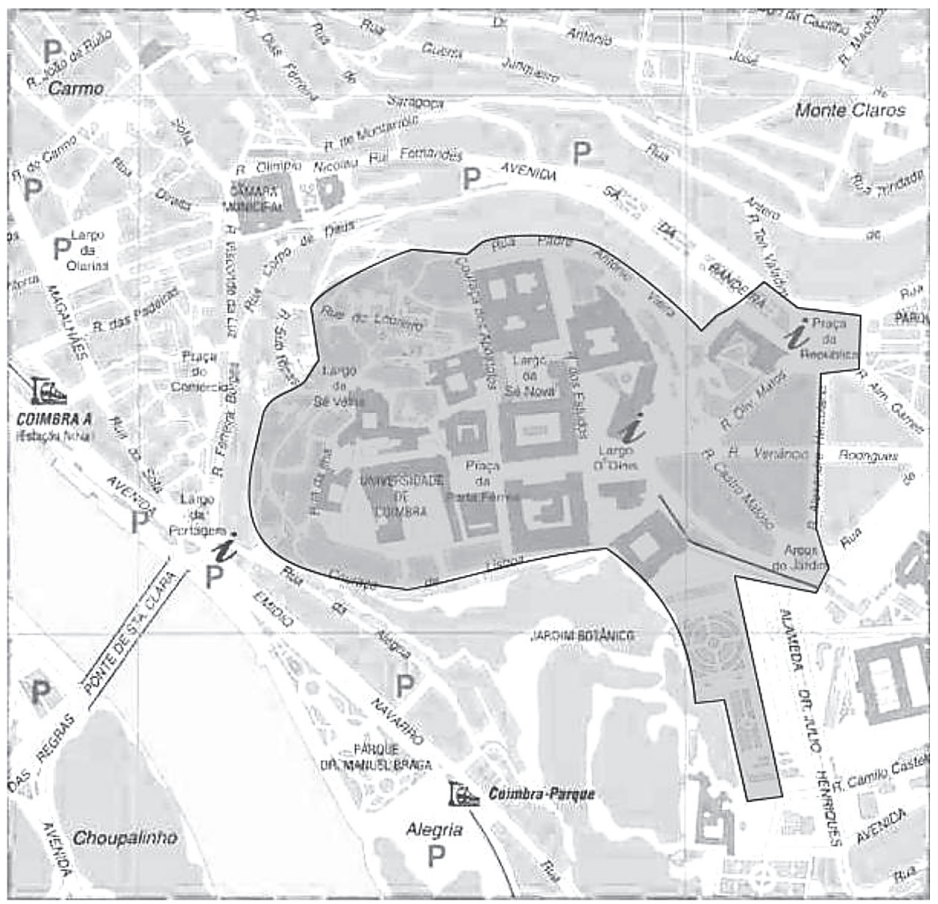

\section{Polo I da Universidade de Coimbra}

Figura 2

Lugar onde decorre a maioria da ação de "Rasganço"

Importa ainda referir que é possível ainda obter uma imagem da urbe de Coimbra através de diálogos ou reflexões manifestadas pelas personagens do "Rasganço". A ideia de uma cidade elitista surge muitas vezes associada a Edgar, mediante expressões como "Despediram-me outra vez. Nunca andei na Universidade..."; a imagem de Coimbra como urbe fragmentada é expressa por Maria dos Anjos para quem, durante um monólogo sobre a personagem central da narrativa (Edgar), "A culpa é desta cidade. São todos uns finaços, acham que só quem andou nesta Universidade é que é gente"; Maria Rita, estudante da Universidade e elemento de uma Lista candidata à Direção da Associação Académica, descreve, através de diálogos (ex. "A nossa luta é muito mais do que isso. É para que pessoas como tu possam continuar a estudar") com Edgar, Coimbra como uma cidade dual e, por último, reflexões como "Quem vê Coimbra daqui, não precisa de ver mais nada. O meu bisavô era professor da Universidade, o meu avô reitor e o meu pai também. 0 meu marido é médico e professor", expressas pela Dr. ${ }^{a}$ Zita durante uma visita, com Edgar ao Convento de santa Clara-a-Nova, transmitem uma imagem da cidade associada a uma sociedade elitista.
Em suma, a imagem veiculada por "Rasganço" apresenta Coimbra como uma cidade que surge associada à Universidade, onde imperam tradições, valores (património intangível) e experiências singulares para quem as vive e inerentes à sua própria tradicionalidade; uma urbe onde impera uma sociedade elitista, fechada para os que chegam; um território onde reside uma realidade dual, ou seja, "uma cidade de estudantes" e a cidade da "população que não faz parte da academia", e, por último, um espaço geográfico fragmentado, com problemas de coesão interna.

Ainda, através da presença do seu património material (geosímbolos) em momentos da narrativa, a película remete Coimbra para um período da história em que esta apresentava grande valor e poder estratégico.

\section{Nota conclusiva}

A imagem surge como um importante instrumento de estratégia de marketing territorial com capacidade de tornar um território sedutor e atrativo. Esta pode construir-se mediante o recurso a mensagens formais e diretas (ex. campanhas promocionais), mas também 
a partir de mensagens informais, como a opinião de amigos ou familiares, livros, criada pelos meios de comunicação (ex. imprensa escrita e media) e indústrias culturais, como é o caso do cinema.

Ao longo dos anos, o cinema tem surgido como um importante instrumento de representação de territórios, e Coimbra não é exceção, uma vez que tem surgido em várias mensagens informais, como sejam produções cinematográficas (curtas e longas-metragens).

A película "Rasganço" aparece como um caso de interesse, não só, pela amplitude da sua divulgação, pelo número de espectadores, mas também pela forma como a cidade é representada. A partir da análise de alguns aspectos do seu conteúdo (lugares percorridos pela ação, diálogos e reflexões das personagens) é possível aferir que a imagem de Coimbra é marcada, nesta produção fílmica, pelo estereótipo de uma urbe fechada, com uma sociedade elitista, como uma cidade com uma realidade dualista.

Neste contexto, a importância das imagens orgânicas na transmissão de representações de um espaço geográfico deve ser alvo de grande atenção, pois esta pode contribuir para a divulgação de uma imagem simplificada e estereotipada. A imagem deve ser vista como um fator com capacidade de contribuir para perda de atratividade e de centralidade de um espaço geográfico. De facto, como referem AzEVEDo et al (2010) "a imagem é um "capital" importantíssimo para o desenvolvimento da gestão da cidade"

\section{Bibliografia:}

Avraham, Eli e Ketter, Eran (2008) - Media strategies for marketing places in crisis. Butterworth-Heinemann, Elsevier, Amsterdam.

Azevedo, António et al (2010) - "City marketing - my place in XXI". Vida Económica Livraria, Lisboa

BAKER, Bill (2007) - Destination branding for small cities. Creative Leap Books, Portland.

Dolıfus, Olivier (1998) - A Mundialização. Publicações EuropaAmérica, Lisboa.

FERnANDES, João (2009) - "Indústrias culturais, representações de lugares e marketing territorial - 0 caso particular do continente africano em O Fiel Jardineiro, de Fernando Meirelles (2005)". SOPCOM/Ibérico, Universidade Lusófona, Lisboa.

Philo, Chris; KeARns, Gerry (1993) - "Culture, history, capital: a critical introduction to the selling of places"; In PHILO, Chris e Kearns, Gerry (Eds.) - Selling Places. The city as cultural capital, past and present. Series Policy, Planning and Critical Theory, Pregamon Press, Oxford.

KotLER, Philip et al (1993) - Marketing places. Free Press, New York.

RaINISTO, Seppo (2010) - "Statement for city marketing - my place"; In AzEVEDo, António et al. (2010) - City marketing - my place in XXI. Vida Económica Livraria, Lisboa 